\title{
Electronic resources in medical libraries: Issues and solutions
}

\author{
Eds. Elizabeth Conner and Sandra Wood
}

New York: Haworth Information Press, 2007. 136p.

ISBN-I 3: 9780789035 I3 4

Price: US\$90 (hbk.)

Co-published simultaneously as Journal of Electronic Resources in Medical Libraries, Vol. 4, Nos. I/2, 2007.

This compilation brings together a collection of ten articles dealing with challenging issues surrounding electronic resources in medical libraries. A list of indexing services and other tools that cover bibliographic access to the articles is provided at the beginning of the book. As the publishers state, this book could be of use to those who do not subscribe to the journal and, according to SACat, only one South African library currently subscribes to the Journal of Electronic Resources in Medical Libraries.

The articles are mostly case studies of American librarians and libraries grappling with various issues surrounding topics like licensing, negotiation of consortia packages, collection development, open access and e-journal pricing, offcampus and across-campus access, publisher liability and the Semantic Web. The book contains a thorough introduction and index. The well written articles include bibliographical references, and the content is delivered in a consistent format, presenting helpful and specific ideas in easily understood language.

Consortium purchasing offers several benefits, at least offering a way for libraries to get more for their pooled money. Members of SANHIP (The South African National Health Information Partnership) would be able to relate to the plans made by libraries and publishers alike in "Moving the Big Deal" to establish win-win opportunities for both parties!

Many questions remain as to whether open access would indeed bring the much needed relief to the relentless rise in journal subscription prices. In her contribution, "Scholarly E-Journal pricing models and open access publishing", Maggie Wineburgh-Freed comes to the conclusion that for the more than 2000 peer-reviewed electronic journals listed in the DOAJ (Directory of Open Access Journals), "...it appears that in most cases these journals have not been viewed as strong enough competition to cause commercial publishers to lower subscription journal prices" (p.22). Will increases from $8 \%$ to $10 \%$ annually be continued, or will libraries cancel their subscriptions to make it clear to publishers they cannot support spiralling prices? It is alarming that "...over $40 \%$ of the Open Access journals are not yet covering their costs", and "...their financial future therefore seems somewhat uncertain" (p.37).

"Extending electronic resource licenses to a newly established overseas medical school branch" by Michael A Wood, Carole Thompson and Kristine M Alpi, describes the importance of collaboration, coordination and the systematic contacting of providers of full-text packages and databases to expand their licenses, with the aim of extending access from Cornell University Libraries in New York to a new e-library in Qatar. Their work resulted in the enhancement of eresource access for their users wherever they are, as the branch libraries are almost 7000 miles (II $265 \mathrm{~km}$ ) apart, with a time difference of eight hours. Thus while most users at one location are asleep, those at the other branch have full access. Both libraries gained financially, as cost sharing resulted in a significant increase in purchasing power. Another clever solution which reduced simultaneous user needs is the curriculum at the Qatar branch, which lags two weeks behind that of the New York branch.

In "Access to health information in Latin America and the Caribbean", the authors provide an overview of the initiative to improve access to health information on a regional level, particularly through cooperative activities and by integrating content available through SciELO and HINARI. They conclude that libraries should explore opportunities to participate in cooperative network environments.

In "Assessing Online Use..." Rick Ralston concludes that the results of his study do not support the reliance on online journal list usage statistics for cancellation decisions. Other factors, such as database client usage patterns and special circumstances that cause them to bypass the online journal list, come into play and should be taken into account.

SA Jnl Libs \& Info Sci 2008, 74(I) 
"Two Interfaces, One Knowledge Base: The development of a combined E-Journal web page", describes the rationale behind this step and how in 2003, two separate libraries within the University of South Carolina successfully collaborated in the implementation of a shared e-journals web page.

The "Off-campus User Behavior" study found that students are increasingly accessing material themselves through online packages and that document delivery requests are decreasing, despite a full document delivery system already available to the students. An area that needs further investigation is establishing whether students are perhaps sacrificing quality for convenience. "If an article is available online now, is that more important than if the better source would take two days or a week to obtain?" (p.82).

For library's lacking an online catalogue, Devica R Samsundar's highly readable and detailed account of how librarians at the Baptist Health South Florida Library, South Miami Hospital, migrated from a traditional catalogue to a web-based interactive online catalogue, is pertinent. Nowadays this is considered a "standard" resource in most libraries. The librarians' creativity and the manner in which they complimented each another in the marketing of the new catalogue are refreshing. Two different approaches were taken to increase the visibility of the new catalogue: an old card catalogue tray was revived as pot plant holder with colourful Impatiens planted in it, and then used as a prop during presentations to highlight the library's move away from the card catalogue. Another approach to highlight the features and functionality of the new OPAC was a PowerPoint presentation patterned on the "Extreme Makeover" television programme.

"As medical library web sites actively participate in electronic delivery, they have the potential to be drawn in as endorsers or actual publishers of erroneous data" (p. I0I). Up until now, the publishing industry has been virtually immune from law suits for erroneous information leading to injury, but given the changing nature of the delivery of published information, this state of affairs may not last for long (p. 102).

All the authors of "Is there a pending change in medical publisher and library liability?" are from the School of Business Administration in Charleston, USA, and they advocate highly visible and thorough disclaimers in the case of medical libraries. Medical publishers are also likely to buy products liability insurance very soon.

If you feel a bit out of date and wonder about phrases like "Semantic negotiation", "domain-specific libraries", "rich conceptual models" and how ontologies differ from taxonomies, you will find Jon Ferguson's "Semantic Web technologies: Opportunity for domain targeted libraries?" enlightening. Not only has the Semantic Web the potential to bring clarity and reliability to web content, but the goal is to make all the data in the world look like one huge database.

While this book examines often time-consuming complexities that librarians face every day, the authors do not claim to have all the answers. However, the useful discussions and conclusions surrounding electronic resources, as well as the importance of cooperation, collaboration and coordination that runs like a golden tread throughout the text, make this an extremely useful source of information.

I would not expect the book to be read extensively. Librarians will be more likely to select articles that deal with their specific areas of interest. Personally, I have gained much from the issues covered, as the variety of approaches, situations and challenges represented in this book, make it an enlightening read. It confirms that tenacity and single-mindedness are much-needed traits for librarians when dealing with electronic resources. There is much to be said for exposure to the detailed information describing how various libraries and publishers respond to the changes brought about by electronic resources. However, in the end, any change will still be driven by the needs of the clients.

In summary, this publication captures many issues that are relevant to various types of libraries, which makes it a suitable information source not only for medical librarians, but for librarians working in general academic libraries, as well as special libraries. Students in the field of Library and Information Science will also benefit from this book.

Reviewed by: Ingrid van der Westhuizen, Librarian, Information Services Division, Health Sciences Library, University of Stellenbosch Library and Information Service, Tygerberg, South Africa.

Tel.: 0219389450 (w)

Email: ivdw@sun.ac.za 